\title{
Bridging the Gaps between eTransforming SMEs and SME - ICT Providers
}

\author{
Ana Hol and Athula Ginige \\ University of Western Sydney, Australia \\ $\{$ a.hol, a.ginige, LNCS $\}$ auws . edu . au
}

\begin{abstract}
Small to Medium Enterprises (SMEs) are struggling to find ICT Providers who could assist them when identifying and implementing adequate Information and Communication Technologies (ICT). Based on this, we conducted a study with 30 SMEs from various industry sectors within Sydney metropolitan region to identify the type of ICT assistance eTransforming SMEs require. Furthermore, to better understand the struggles SMEs go through, we also studied eight ICT Providers. Our findings indicate that in order for the SMEs to successfully eTransform, select and implement appropriate ICT there is need for the ICT Providers to bridge the gaps and understand needs and requirements of the eTransforming companies taking into consideration a holistic view of what eTransforming SMEs need based on their current technology and future business requirements.
\end{abstract}

Keywords: SMEs, eTransformation, Information and Communication Technology, ICT providers.

\section{Introduction}

Today, society has changed, and we have become more dependent on technologies that surround us. For the business to be successful they are required to embrace technology. Successful communication with customers and business partners means a successful business. For the customers to be satisfied there is a need for a business to have an online presence. In order to do this, SMEs are required to eTransform, select and implement appropriate ICT.

eTransformation is a process through which companies need to go through so that they can have required skills and technologies to be able to survive in ICT centered world [1]. There are many models that explain oranisational change and ICT implementation [2-11]. One of the models that very comprehensively assess ICT selection and implementation within the organisation is the eTransformation Road Map [1] presented in the table below.

From the table above it can be seen that eTransformation is a staged process and that in order for SMEs to reach a desired level of eTransformation, they need to successfully complete each preceding stage. For example a company's desired stage may 
be Stage 2. To reach Stage 2 they will need to complete all Stage 1 requirements. From this we conclude that in order for the eTransformation process to be successful, ICT Providers would need to take an eTransforming SMEs through each eTransformation stages, step by step. Through this research we explore at what stage current eTransforming SMEs are at and also whether ICT Providers are skilled and able to assist SMEs to eTransform further.

Table 1. eTransformation Stages and Accompanying Technologies - adapted from [1]

\begin{tabular}{|c|c|c|}
\hline \multicolumn{2}{|r|}{ Stage } & Hardware, Software and Networking infrastructure \\
\hline \multirow[t]{2}{*}{ Stage 1} & Effective Individual & $\begin{array}{l}\text { Individuals with stand-alone computers having } \\
\text { productivity software such as accounting packages } \\
\text { spreadsheets, word processors etc installed. Possibly } \\
\text { dial up connection to the Internet for individual email } \\
\text { accounts. }\end{array}$ \\
\hline & Basic Web Site & $\begin{array}{l}\text { Organisation having its own domain name and "Brochure } \\
\text { ware" type web site hosted with an ISP. }\end{array}$ \\
\hline \multirow[t]{2}{*}{ Stage 2} & Effective Team & $\begin{array}{l}\text { Computers are networked. People can work in teams } \\
\text { using networked applications. Providing email and } \\
\text { Intranet capabilities can enhance productivity of a team. }\end{array}$ \\
\hline & Interactive Web Site & $\begin{array}{l}\text { Organisations having Web sites that provide two-way } \\
\text { flow of information. From these Web sites uses should be } \\
\text { able to get immediate responses to structured queries } \\
\text { such as a quotation for a particular product configuration } \\
\text { user has selected. Also another feature would be to } \\
\text { provide personalised information to frequent visitors. } \\
\text { These types of Web sites though can be hosted with an } \\
\text { ISP are better to host on site. This requires a Web server } \\
\text { and a high-speed dedicated connection to the Internet. }\end{array}$ \\
\hline \multirow[t]{2}{*}{ Stage 3} & $\begin{array}{l}\text { Effective } \\
\text { Organisation }\end{array}$ & $\begin{array}{l}\text { Organisation now uses enterprise wide applications; a } \\
\text { single application that supports different sections of the } \\
\text { organisation such as purchasing, sales, accounting, } \\
\text { manufacturing etc. thus enabling information integration } \\
\text { and sharing across enterprise. }\end{array}$ \\
\hline & eCommerce Site & $\begin{array}{l}\text { At this stage the organisation should have secure Web } \\
\text { servers to facilitate financial transactions or a link to a } \\
\text { payment get way to get this facility. }\end{array}$ \\
\hline Stage 4 & Convergence & $\begin{array}{l}\text { Organisation has now achieved integration of information } \\
\text { that needs to support all its business processes. The flow } \\
\text { of information of an organisation that has reached the } \\
\text { level of convergence. }\end{array}$ \\
\hline
\end{tabular}

\section{ICT Requirements as Perceived by eTransforming SMEs}

Therefore, to better understand needs and requirements of the eTransforming SMEs, 30 SMEs from Sydney metropolitan region were studied. A list of represented industry sectors is presented in the table below. 
Table 2. Industry sectors representing 30 SMEs

\begin{tabular}{|l|r|}
\hline Industry Sector & No. of SMEs \\
\hline Accounting and Consulting & 1 \\
\hline Building & 2 \\
\hline Community Services and Hospitality & 1 \\
\hline Consultancy & 4 \\
\hline Construction & 1 \\
\hline Education and Training & 1 \\
\hline Finance & 2 \\
\hline Funeral Services & 1 \\
\hline Health and Wellbeing & 2 \\
\hline Manufacturing & 5 \\
\hline Organic food & 1 \\
\hline Photography and Picture Framing & 1 \\
\hline Printing & 1 \\
\hline Retail, Sales \& Speciality & 2 \\
\hline Services & 1 \\
\hline Tourism Hospitality & 3 \\
\hline Training in Sales and Marketing & 1 \\
\hline Total & 30 \\
\hline
\end{tabular}

Each company that has willingly agreed to participate within the study was interviewed. Interviews lasted about $1 \mathrm{~h}$ 30min. During the interviews studied SMEs were mapped on the eTransformation Road Map. The results are displayed in Figure 1.

Based on the analysis majority of eTransforming SMEs are currently at level 0 (no website) and 1 (basic website) and a small number on level 2 (interactive site) within the eTransformation Road Map. This means that companies mostly have basic websites, however that there are still those who do not. Furthermore, findings show that studied SMEs use basic productivity tools such as Word, Excel, PDFs. They also use e-mails and file storage media. However, companies are still struggling to integrate their ICT and move towards effective teams.

In addition, studied SMEs were asked to point out the areas of ICT in which they felt that they should improve in. All companies stated that they would need to develop their online identity which would mean design, re-creation and re-shaping of their current websites. Companies also stated that this is extremely hard for them as ICT companies expect them to know exactly what they would like to have on their sites without giving them much opportunity to experiment and identify possibilities.

Furthermore, eTransforming SMEs identified that if they are to move ahead and integrate some of their current systems they are faced with huge challenges. They also report that SME- ICT Providers somehow do not get the full understanding of their requirements. In addition, eTransforming SMEs report that they are struggling to set up networks, share data and establish remote access. They also state that it is extremely hard to identify what type of ICT will be the most beneficial for their own business. Moreover, it is exceptionally hard for the SMEs to keep up with new technology and therefore they need ICT Providers to help them identify what is absolutely crucial for their own business. 


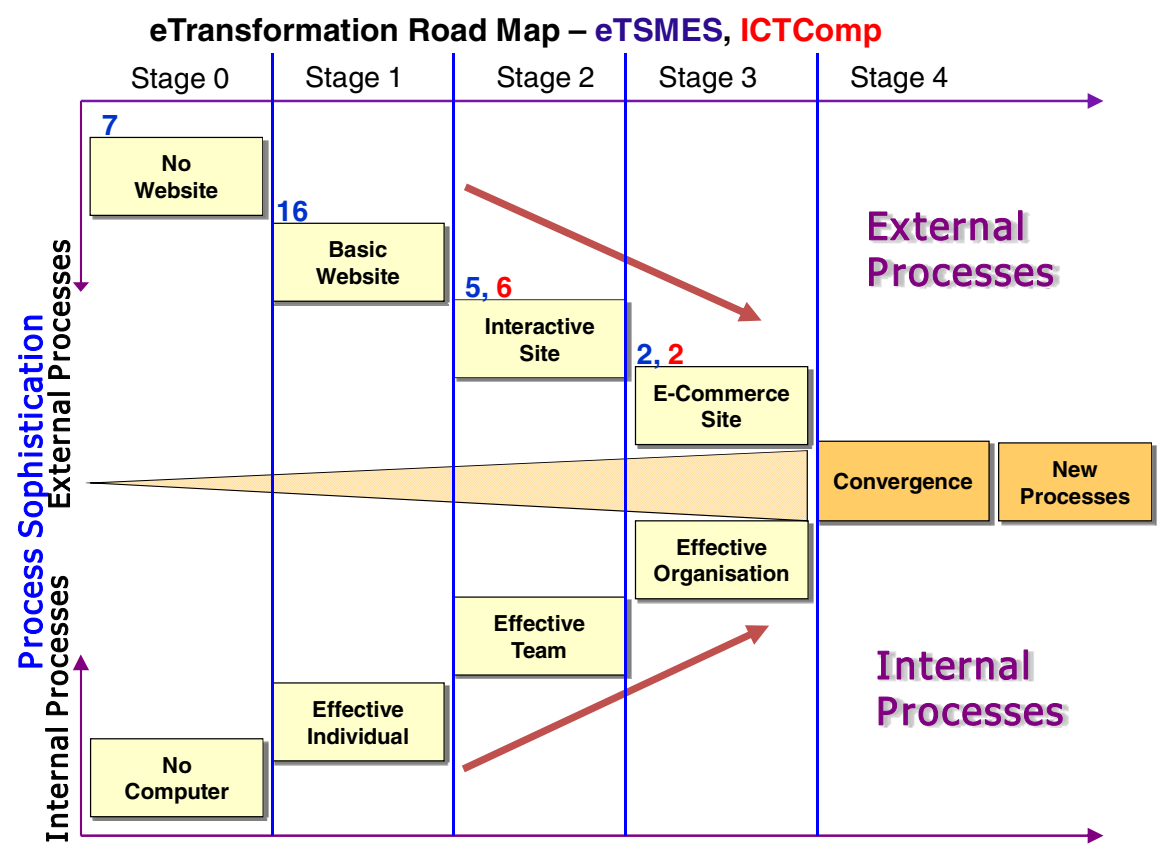

Fig. 1. eTransformation Road Map [1]

ICT Maintenance and Support seem to be a big problem for eTransforming SMEs too. They state that for them it is impossible to find someone who will reliably look into their systems and therefore they are finding that it is the most suitable to rely on help from relatives or friends. They also feel that in order to get some help and advice from the ICT Providers they need to pay for consultations and advice which they are unable to afford and therefore lack holistic support.

In addition, a majority of eTransforming SMEs have identified that in order to survive in the electronic world they will need to undertake training. It appears, based on the data collected via the interviews, that training in handling business online, managing business web pages and communicating via social networking sites with the customers is becoming increasingly important. Moreover, companies feel that they require training in graphical design and document management.

Following the identification that eTransforming SMEs require assistance across both internal and external ICT processes (see Figure 1 for details) and that they are struggling to get it, through this study we aim to identify how best needs and requirements of the eTransforming SMEs can be met by studying a group of SME - ICT Providers.

\section{ICT Providers}

Following the study with 30 SMEs we have decided to select a group of SME size ICT Providers within a metropolitan Sydney region to identify if these companies are able to meet needs and demands of the eTansforming SMEs. 
Eight ICT Provider companies that willingly agreed to participate within the study were interviewed. During the interviews companies were asked about jobs that they performed. Their ability and past experiences were taken into the consideration too. Collated data was used to map ICT Provider companies on the eTransformation Road Map to identify their current ICT development. Results for ICT Providers, shown in red, are depicted in Figure 1. Findings indicate that a majority of ICT Provider companies are in Stage 2 of eTransformation development, that they have interactive websites, are able to manipulate data electronically and are slowly implementing integrated systems.

Based on the data collected and the understanding that ICT Providers have embraced technology more than eTransforming SMEs from other industry sectors we further investigated to what extent ICT companies are able to meet needs and demands of the SMEs requiring technical assistance.

\section{ICT Providers: Can They Assist eTransforming SMEs?}

Based on the developmental process identified within the eTransformation Road Map each developmental stage (0-4) was converted into a number of questions and based on it given rating. For example, if a studied ICT Provider was able to complete all that was required for the SME to have a website within the Stage 1 the ICT Provider would be given a rating of 1 . If the ICT Provider was only partially able to complete the tasks the company would be given a rating of 0.5 . This rating would mean that the ICT Provider has answered positively to a minimum of $50 \%$ of the questions within this section but less than $100 \%$. If ICT Provider was able to complete activities less than $50 \%$ the provider would be given a rating of 0 . Table 3 shows the rating for all 8 ICT Providers.

Based on the data within the table it can be seen that none of the 8 providers is able to complete a task across all stages (0-4). Moreover, it can also be seen that even if all resources of the ICT companies are to be combined there would still be areas in which support would be lacking.

From the data depicted in Table 3 it can be seen that only one ICT Provider (company 6) is able to fully complete Stage 1 , and that company 8 is missing half a point to be able to do the same. None of the ICT Providers is able to complete Stage 2 in full. The closest one to completing the Stage 2 is company 6 (lacking 1 point). Stage 3 was far from reach for all ICT Providers (company 6 was lacking 3 points). When looking at the collective skills of 8 ICT Provides (Figure 2) it can be seen that Stage 1 and Stage 2 can be completed to almost $70 \%$ successfully. Stage 2 however is not well represented and there are many areas that are lacking and do not even reach 50\% development, such as infrastructure, application and systems implementation and web set up and support. It can also be seen that Stage 3 can only be completed 30\% successfully. Therefore, we conclude that in order for the eTransformation to be successfully carried gaps between eTransformation requirements and ICT Provider skills would need to be bridged. 
Table 3. Ratings for ICT Providers

\begin{tabular}{|c|c|c|c|c|c|c|c|c|c|c|}
\hline ICT Providers & Comp 1 & Comp2 & Comp3 & Comp4 & Comp5 & Comp6 & Comp7 & Comp8 & TOTAL & $\begin{array}{l}\% \\
\text { out } \\
\text { of } \\
8\end{array}$ \\
\hline Web design development 1 & 0.5 & 1 & 0 & 1 & 1 & 1 & 1 & 1 & 6.5 & 81.25 \\
\hline Web set up support 1 & 0.5 & 0.5 & 0 & 0.5 & 1 & 1 & 1 & 1 & 5.5 & 68.75 \\
\hline Security 1 & 1 & 0.5 & 1 & 1 & 1 & 1 & 0.5 & 1 & 7 & 87.5 \\
\hline Infrastructure 1 & 1 & 0.5 & 0.5 & 1 & 0.5 & 1 & 0.5 & 1 & 6 & 75 \\
\hline Training 1 & 1 & 1 & 1 & 1 & 1 & 1 & 0.5 & 0.5 & 7 & 87.5 \\
\hline Applications systems 1 & 1 & 0 & 1 & 0.5 & 0.5 & 1 & 0.5 & 1 & 5.5 & 68.75 \\
\hline Web design development 2 & 0 & 1 & 0 & 1 & 1 & 1 & 1 & 1 & 6 & 75 \\
\hline Web set up support 2 & 0 & 0.5 & 0 & 0.5 & 1 & 0.5 & 0.5 & 0.5 & 3.5 & 43.75 \\
\hline Security 2 & 1 & 0 & 1 & 1 & 0.5 & 1 & 0.5 & 1 & 6 & 75 \\
\hline Infrastructure 2 & 0.5 & 0 & 0.5 & 1 & 0 & 1 & 0 & 0.5 & 3.5 & 43.75 \\
\hline Training 2 & 0.5 & 1 & 1 & 1 & 1 & 1 & 0 & 0 & 5.5 & 68.75 \\
\hline Applications systems 2 & 0.5 & 0 & 0.5 & 0 & 0.5 & 0.5 & 0 & 0.5 & 2.5 & 31.25 \\
\hline Web design development 3 & 0 & 0.5 & 0 & 0.5 & 1 & 0.5 & 1 & 1 & 4.5 & 56.25 \\
\hline Web set up support 3 & 0 & 0.5 & 0 & 0 & 0.5 & 0.5 & 0.5 & 0.5 & 2.5 & 31.25 \\
\hline Security 3 & 0 & 0 & 0.5 & 0.5 & 0 & 0.5 & 0 & 0.5 & 2 & 25 \\
\hline Infrastructure 3 & 0.5 & 0 & 0.5 & 0.5 & 0 & 0.5 & 0 & 0.5 & 2.5 & 31.25 \\
\hline Training 3 & 0 & 0.5 & 0.5 & 1 & 0.5 & 0.5 & 0 & 0 & 3 & 37.5 \\
\hline Applications systems 3 & 0.5 & 0 & 0.5 & 0 & 0.5 & 0.5 & 0 & 0 & 2 & 25 \\
\hline
\end{tabular}

\section{$81 \%$ Web design / development \\ $69 \%$ Web set up / support \\ $75 \%$ Web design / development \\ $44 \%$ Web set up / support}

\section{ICT Providers on the \\ eTransformation Road Map}

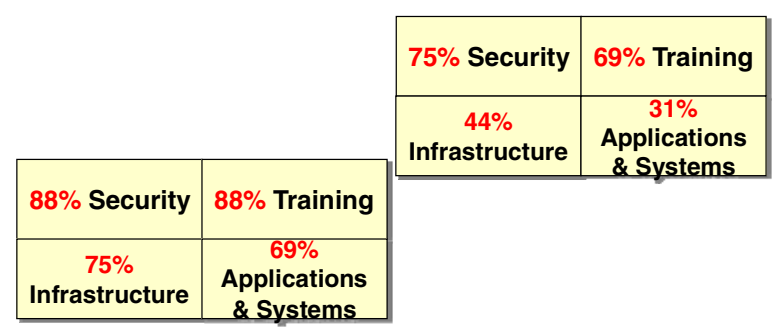

\section{External Processes}

$56 \%$ Web design / development

$31 \%$ Web set up / support

\begin{tabular}{|c|c|}
\hline $25 \%$ Security & $38 \%$ Training \\
\hline $31 \%$ & $\begin{array}{c}25 \% \\
\text { Applications } \\
\text { \& Systems }\end{array}$ \\
\hline
\end{tabular}

Internal Processes

Fig. 2. Grouped Skills of Eight ICT Provides Shown on the eTransformation Road Map 


\section{Bridging the Gaps between eTransformation Requirements and ICT Providers}

Based on the findings it appears that in the form in which ICT Provides are currently operating in, it is virtually impossible for them to fully meet needs and demands of eTransforming SMEs. ICT Providers seem to be specialising in very narrow fields. None of the interviewed providers looks at eTransforming SMEs holistically. They tend to focus only within the area they service. For example, if a company is designing websites they will create the site but will rarely take into the consideration the industry sector the SME needing the website is in, nor other systems the SME has nor the system integration and data and file transfers. Therefore, it becomes very hard for the SMEs to get the appropriate websites and systems. Consequently, to eTransform SMEs are required to see a business analyst, a network specialist, web designer and hardware and software specialists in order to transform. However, even then, it is extremely hard to assure that all components selected will be compatible.

Therefore, we speculate that the way how ICT Providers are assisting SMEs will need to be changed. First of all for the SMEs to get the eTransformation assistance it would be necessary for the businesses to be reviewed holistically. Furthermore, it will be essential for the specialists within the ICT industry to communicate with one another and work with the same understanding of business needs and requirements. They would all need to understand what the SME is intending to achieve by eTransforming. They would also need to know how the SME is planning to work and operate. Are they going to operate online? Will they continue to operate as a brick and mortar company? Furthermore, ICT specialists will need to understand the business operations of the companies they are assisting so that they can guide them in selecting and implementing required ICT. Moreover, it is essential for the ICT Providers to understand systems eTransforming SMEs already have, as well as identify how their existing tools and systems will fit with new system upgrades and applications.

Past research indicates that eTransformation Guide (eT Guide) can be used by SMEs to help them track, guide and measure their eTransformation journey [12]. The eT Guide through a series of questions about Strategy - company vision goals and objectives; Structure - company departments and divisions followed by Business Tasks and Processes - automation, streamlining and integration allows the SME to build a personalised eTransformatgion Report that identifies SMEs current Abilities - what the SME can currently do with the technology they have and the Recommendations - what the SME could do in the future in order to advance and successfully eTransform allows the SMEs to take a charge of their eTransformation journey (Figure 3).

We believe that if eTransforming SMEs are encouraged to take eTransformation initiative and start monitoring their eTransformation journey via the eT Guide they would much easier be able to communicate with ICT Providers. Furthermore, this would also mean that each ICT Provider would be able to understand the company's current eTransformation status and would easier be able to identify tools and systems SMEs would need to successfully eTransform.

We also speculate that for ICT Providers to be able to provide full assistance they could work collaboratively or in clusters. Their operations would be similar to those of toolmaking SMEs example [13] where SMEs would be able to take more complex 


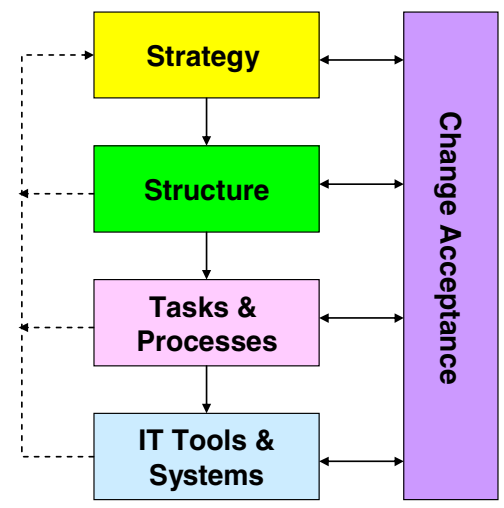

Fig. 3. Iterative Model of eTransformation [12]

and bigger jobs by sharing their equipment and splitting the jobs amongst themselves with the aim of getting bigger projects. Similar could happen with ICT providers were for example analyst, a web developer, a graphic designer, a networking specials and hardware and software specialists search for jobs collectively. Furthermore, they may work collaboratively in a way so that once a business analysis is done for the company depending on their needs and requirements specialists may meet together to discuss the requirements and then split the jobs amongst themselves in accordance to the SME needs.

This further meets with earlier speculations of dynamic enterprise collaborations where companies from same or different industry sectors may meet per project to complete particular tasks or actions. This further indicates that companies within SME sectors will need to create business networks in order to complete tasks and processes and remain competitive within the global markets. However, for the ICT Providers to do so, they will first need to gain an understanding that it is essential to know the business holistically first, before appropriate ICT tools and systems can be selected and implemented. In addition, it can be seen that if the group of eight ICT Providers was to collaborate they would need to be able to identify skills that they as a group have and then identify skills they are missing to be able to assist eTransforming SMEs.

\section{Conclusion}

It is not surprising to see why eTransforming SMEs are struggling to identify and select required ICT so that they can easily survive in the digital economy. This study identifies that SMEs are experiencing difficulties when required to identify ICT Providers that could help them select and implement ICT tools and systems they need. They are faced with ICT Providers who specialise in specific ICT areas and who are unable to provide holistic guidelines as each ICT Provider is mainly concerned with their own area of expertise and therefore do not take into the consideration eTransforming SME goals and objectives nor their existing tools and systems into considerations while providing 
support. Furthermore, we also identify that eTransforming SMEs could use the eTransformation Guide to take control of their eTransformation journey and with it also help ICT Providers to understand current state of their eTransformation and so help them identify tools and systems required.

We also identify that in order for the ICT Providers to be able to help eTransforming SMEs holistically they may need to make collaborative arrangements amongst one another as well as with the other related industries to be able to get a more holistic views of the SMEs requirements. The collaborative arrangements could also help ICT Providers meet demands placed by the eTransforming SMEs easier as well as in turn make the SMEs more productive in the electronic environment.

\section{References}

1. Ginige, A., Murugesan, S., Kazanis, P.: A Road Map for Successfully Transforming SMEs into eBusiness. Cutter IT Journal 15(5), 13 (2001)

2. Waterman, R.H., Peters, T.J., Phillips, J.R.: Structure is Not Organization. Business Horizons 23(3), 14-26 (1980)

3. Mawson, A.: The Advanced Organisation, New Models for Turbulent Times (2002), http : / / www. advanced-workplace.com (retrieved February 27, 2006)

4. People and Process. Business Crisis Management (2005), http: //www. the-process-improver.com/ business-crisis-management.html (retrieved March 3, 2006)

5. Earl, M.J.: Management Strategies for Information Technology. Burr Ridge, Irwin (1989)

6. Burn, J., Ash, C.: A Dynamic Model of E-business Strategies for ERP Enabled Organisations. Industrial Management \& Data Systems 105(8), 1084-1095 (2005)

7. Galliers, R.D., Merali, Y., Spearling, L.: Coping with Information Technology? How British Executives perceive the key information systems management issues in the mid 1990s. Journal of Information Technology 9, 223-238 (1994)

8. McKay, J., Prananto, A., Marshall, P.: E-Business Maturity: The SOG-e Model. In: Proceedings of the ACIS - 11th Australasian Conference on Information Systems, Brisbane, Australia, December 6-8 (2000)

9. Wons, E.: Organisational Change - An Ethical, Means Based, Approach, JPC Training \& Consulting LLC, Boston (1999)

10. Nolan, R.L.: Managing the Crises in Data Processing. Harvard Business Review 57(2), $115-116$ (1979)

11. Rayport, J.F., Jaworski, B.J.: Introduction to E-Commerce, Boston (2002)

12. Hol, A., Ginige, A.: eTransformation Guide: An Online System for SMEs. In: 3rd IEEE International Conference on Digital Ecosystems and Technologies, Istanbul, Turkey, June 1-3 (2009)

13. Lawson, R., Arunatileka, S., Ginige, A., Hol, A.: A Pilot Project on eCollaboration in the Australian Toolmaking Industry 18th Bled eConference eIntegration in Action, Bled, Slovenia, June 6-8 (2005) 